\title{
Editorial
}

Cite this article as: Libyan J Med, AOP:060601 (published 01 September 2006)

\section{Libyan Journal of Medicine: a humble, but a vital step!}

The Editorial Board

Libyan Journal of Medicine

Dear Readers,

Members of the editorial board of the Libyan Journal of Medicine (ljm) welcome you to the celebration of the birth of its first online issue (September 2006).

You may wonder about the need for another medical journal added to the many journals currently published. With the internet and global thinking, the planet has become a world medical village. With this in mind, a group of enthusiastic Libyan medical scientists looked at the contributions of the Libyan medical publications to the international medical literature, and it was immediately clear that something was missing.

To fill this gap, we decided to launch the ljm, with the goal that the journal will function as a tool to transfer current medical knowledge to and from colleagues in developing countries, particularly, Libya.

The journal production is a team effort led by a group of Libyan physicians inside and outside Libya, who welcome the support of colleagues from the international medical community, including members who have no roots in Libya. The journal's focus will be to document the experiences of physicians worldwide and to promote health education.

This focus is in line with our duty of prevention and treatment of diseases. Publications of medical experiences and research results help clinicians and investigators improve their quality assurance programs. The $\mathrm{ljm}$ is a free, open-access, peer-reviewed journal participating in the spread of medical knowledge to all. As a 
first step in its publication, we request feedback from readers, so that improvements can be made to develop a journal that is considered vital to its readers.
Please do send us your comments about the journal or the website.

The Editorial Board

Libyan Journal of Medicine June 6th, 2006 